\title{
Silymarin nanoparticle prevents paracetamol-induced hepatotoxicity
}

This article was published in the following Dove Press journal:

International Journal of Nanomedicine

2I June 20II

Number of times this article has been viewed

\section{Suvadra Das \\ Partha Roy \\ Runa Ghosh Auddy \\ Arup Mukherjee}

Department of Chemical Technology, University of Calcutta, Kolkata,

West Bengal, India
Correspondence: Arup Mukherjee Department of Chemical Technology, University of Calcutta, 92, A.P.C. Road, Kolkata 700009, West Bengal, India

$\mathrm{Tel}+9 \mid 3323508386$

$\mathrm{Fax}+913323519755$

Email arupm1234@gmail.com
Abstract: Silymarin (Sm) is a polyphenolic component extracted from Silybum marianum. It is an antioxidant, traditionally used as an immunostimulant, hepatoprotectant, and dietary supplement. Relatively recently, Sm has proved to be a valuable chemopreventive and a useful antineoplastic agent. Medical success for Sm is, however, constrained by very low aqueous solubility and associated biopharmaceutical limitations. Sm flavonolignans are also susceptible to ion-catalyzed degradation in the gut. Proven antihepatotoxic activity of Sm cannot therefore be fully exploited in acute chemical poisoning conditions like that in paracetamol overdose. Moreover, a synchronous delivery that is required for hepatic regeneration is difficult to achieve by itself. This work is meant to circumvent the inherent limitations of Sm through the use of nanotechnology. Sm nanoparticles (Smnps) were prepared by nanoprecipitation in polyvinyl alcohol stabilized Eudragit RS100 ${ }^{\circledR}$ polymer (Rohm Pharma GmbH, Darmstadt, Germany). Process parameter optimization provided $67.39 \%$ entrapment efficiency and a Gaussian particle distribution of average size $120.37 \mathrm{~nm}$. Sm release from the nanoparticles was considerably sustained for all formulations. Smnps were strongly protective against hepatic damage when tested in a paracetamol overdose hepatotoxicity model. Nanoparticles recorded no animal death even when administered after an established paracetamol-induced hepatic necrosis. Preventing progress of paracetamol hepatic damage was traced for an efficient glutathione regeneration to a level of $11.3 \mu \mathrm{mol} / \mathrm{g}$ in hepatic tissue due to Smnps.

Keywords: silymarin, paracetamol, nanoparticle, glutathione, mouse hepatotoxicity

\section{Introduction}

Paracetamol (N-acetyl- $\rho$-aminophenol, APAP) is an antipyretic analgesic, available over-the-counter. The drug, however, is toxic in high dosages and an overdose of $4 \mathrm{~g}$ /day can cause hepatic necrosis. ${ }^{1}$ APAP hepatotoxicity is marked in alcoholics and in patients undergoing multiple drug treatment like that in human immunodeficiency virus HIV infections or in tuberculosis. ${ }^{2,3}$ A number of reports also exist on suicidal attempts by ingestion of APAP. ${ }^{4}$ APAP is metabolized in the liver to form soluble sulfates and glucuronides. A small amount is converted in the microsomal cytochrome P450 enzyme system into the reactive metabolite $\mathrm{N}$-acetyl$\rho$-benzoquinone-imine (NAPQI). ${ }^{5,6}$ At low dosages, the amount of NAPQI formed gets conjugated to the hepatic reduced glutathione (GSH) store, before being eliminated. In case of APAP overdose or in conditions when the hepatic GSH store is depleted, NAPQI reacts further with cellular proteins causing oxidative stress, microsomal membrane damage, and cell death. ${ }^{7}$ With the liver being the most oxidative organ, increased oxidative stress induces apoptosis. 
Silymarin (Sm) is a polyphenolic component isolated from the fruits and seeds of the milk thistle plant Silybum marianum (family Asteraceae). ${ }^{8,9}$ Milk thistle extracts have been used for over 2000 years ${ }^{10}$ by different civilizations as rejuvenators. Chemically, $\mathrm{Sm}$ is a mixture of flavonolignan isomers ${ }^{11,12}$ of general molecular formula $\mathrm{C}_{25} \mathrm{H}_{22} \mathrm{O}_{10}$. Silybin constitutes the principal chemical component in the purified extract. ${ }^{13}$

Interest has been renewed in $\mathrm{Sm}$ for a variety of reasons including the discovery of its chemopreventive, anti-angiogenic, and anticancer potentials. ${ }^{14,15}$ The drug, however, suffers from biopharmaceutic limitations due to very poor aqueous solubility, ${ }^{16,17}$ inappropriate tissue distribution, and degradation in the gastric environment. ${ }^{18}$ Attempts were made to solubulize $\mathrm{Sm}$ in order to overcome biopharmaceutic limitations but none of these have met with any pharmacological successes. ${ }^{19,20}$ A phospholipids complex of silybin was proposed to improve solubility and permeability. ${ }^{21}$ Salts of Sm were attempted but were limited by membrane permeability. A liposomal delivery system for Sm was reported ${ }^{22}$ but suffers from high surfactant content and low entrapment efficiency.

Sm flavonolignans exert multilateral activity on hepatocytes. Sm promotes hepatocyte ribonucleic acid (RNA) polymerase I, facilitates adenosine 5'-triphosphatase (ATPase) activity, and restores GSH content. ${ }^{23}$ Hepatoprotection is a synchronous activity of flavonolignans to hasten mitotic activity and thereby leads to regeneration of liver tissue. ${ }^{24}$ Additionally, Sm components are strong inhibitors of leukotrienes and proinflammatory transmitters like nuclear factor kappa B (NF- $\mathrm{BB}){ }^{25,26} \mathrm{Sm}$ has great potential for long-term hepatoprotection against chemotoxic agents like APAP and might even offset hepatic damage. ${ }^{27-29}$

This work was aimed to develop a slow release nanoparticle delivery device for Sm in order to circumvent solubility limitations. Nanoprecipitation technique was preferred over others for easy adaptability in scaling up. Eudragit RS100 ${ }^{\circledR}$ (Rohm Pharma GmbH, Darmstadt, Germany), a polycationic acrylate copolymer, was successfully used for Sm nanoparticulation. The polymer is insoluble at physiological $\mathrm{pH}$ ranges but swells partially in water. Cationic Eudragit nanoparticles allow specific advantages and were previously used in oral and ophthalmic nanoparticle delivery devices. ${ }^{30,31}$ Polyvinyl alcohol, PVA, was used as a stabilizer. PVA can provide nanoparticle steric and mechanical stabilization ${ }^{32}$ but has not previously been evaluated with Eudragit nanoparticles.
Factorial design experiments were attempted to optimize the nanoparticle size and entrapment efficiency. Both protective and restorative animal experiments were used to assess the efficacy of Sm nanoparticles (Smnps) as an impediment to APAP-induced necrosis. Mouse models were preferred over rat, as NAPQI-mediated hepatic damage is more pronounced..$^{33,34}$

\section{Materials and facilities}

Borosil $^{\circledR}$ (Mumbai, India) glassware was used for preparation and analysis experiments. A precision balance $0.00001 \mathrm{~g}$ Mettler $^{\circledR}$ Toledo AL54 (Mettler, Columbus, OH), an ultracentrifuge Himac CS120GHXL (Hitachi Koki, Tokyo, Japan), and Accupipet Tarsons (Tarsons, Kolkata, India) were used in preparative processes. Zetasizer ${ }^{\circledR}$ Nano ZS (Malvern Instruments, Malvern, UK), UV-vis spectrophotometer UV-2550 (Shimadzu, Kyoto, Japan), Atomic Force Microscope Nanoscope 3A (Veeco, Plainview, NY), and FT/ IR-670 plus (Jasco, Tokyo, Japan) were used for analytical and particle characterization. Homogenizer TH 02 (Omni International, Kennesaw, GA) and a microscope (B1 series, Motic, Xiamen, China) were used for biochemical analysis and animal experiments. Solvents and water used were of high-performance liquid chromatography (HPLC) grade and were procured from E Merck or Spectrochem (Mumbai, India). Dialysis tubing D9652 (MW cut off $12,400 \mathrm{kD}$ ), Sm, PVA (89,000-98,000 kD), 5,5'-dithiobis (2-nitrobenzoic acid) (DTNB) were purchased from Sigma-Aldrich ( $\mathrm{St}$ Louis, MO). Diagnostic kits for biochemical studies were obtained from Merck Specialties Private Ltd (Mumbai, India). Eudragit $\mathrm{RS} 100^{\circledR}$ was a gift from Rohm Pharma $\mathrm{GmbH}$. Paracetamol was a gift sample from Dey's Medical Stores (Mfg) Ltd (Kolkata, India). Windows Excel (v 2003; Redmond, WA) and Sigmaplot (v 6.0; Jandel Scientific) were used for most data analysis purposes.

\section{Methods}

\section{Preparation of Smnps}

Smnps were prepared following a nanoprecipitation technique. Different preparations were designed varying in stabilizer PVA and the Eudragit RS100 ${ }^{\circledR}$ polymer mass used (Table 1). In a typical experiment, $10 \mathrm{mg}$ of Sm and $200 \mathrm{mg}$ of Eudragit RS $100^{\circledR}$ were dissolved together in $1 \mathrm{~mL}$ of ethanol in a sealed glass vial. Nine milliliters of $2 \% \mathrm{w} / \mathrm{v}$ aqueous solution of PVA was then added slowly with magnetic stirring. Stirring was continued for an additional period of 10 minutes and $10 \mathrm{~mL}$ of water was then added as a 
Table I Particle size, zeta potential, and silymarin entrapment in nanoparticles

\begin{tabular}{|c|c|c|c|c|c|c|c|}
\hline $\begin{array}{l}\text { Preparation } \\
\text { type }\end{array}$ & $\begin{array}{l}\text { Silymarin } \\
\text { mass (mg) }\end{array}$ & $\begin{array}{l}\text { Eudragit RS } \\
100(\mathrm{mg})\end{array}$ & $\begin{array}{l}\text { PVA } \\
\text { (\% w/v) }\end{array}$ & $\begin{array}{l}\text { Silymarin } \\
\text { entrapment* \% }\end{array}$ & $\begin{array}{l}\text { Particle } \\
\text { size* (nm) }\end{array}$ & PDI* & $\begin{array}{l}\text { Zeta } \\
\text { potential* }(\mathrm{mV})\end{array}$ \\
\hline $\mathrm{BI}$ & 10 & 200 & 4 & $55.10 \pm 1.12^{*}$ & $89.86 \pm 4.27^{*}$ & $0.255 \pm 0.02$ & $+\mid 7.60 \pm 1.21$ \\
\hline B2 & 10 & 200 & 2 & $67.39 \pm 4.32^{*}$ & $120.37 \pm 2.11^{\S}$ & $0.262 \pm 0.01$ & $+27.7 \pm 2.67$ \\
\hline B3 & 10 & 100 & 4 & $55.27 \pm 5.68^{*}$ & $100.08 \pm 3.30^{*}$ & $0.257 \pm 0.03$ & $+23.2 \pm 3.55$ \\
\hline B4 & 10 & 100 & 2 & $34.75 \pm 3.18$ & $132.46 \pm 5.25$ & $0.344 \pm 0.06$ & $+29.5 \pm 1.08$ \\
\hline
\end{tabular}

Notes: *Results expressed as mean $\pm S D(n=3) ;{ }^{¥} P<0.01$ significant difference compared with $B 4 ; \$ \$ P<0.05$ no significant difference compared with $B 4$. Abbreviations: PDI, polydispersity index; PVA, polyvinyl alcohol; SD, standard deviation.

nonsolvent for nanoprecipitation. Nanoparticles formed were collected by ultracentrifugation at $30,000 \mathrm{rpm}$ for $30 \mathrm{~min}$ utes at $4{ }^{\circ} \mathrm{C}$ and the recovery ${ }^{35}$ recorded was $96 \pm 3.9 \%$. The particles were resuspended in water, recentrifuged, collected, and preserved in vacuum desiccators at $4{ }^{\circ} \mathrm{C}$ until further experiments. Factorial design based experiments $\left(2^{2}\right)$ were carried out to understand effect of change on preparation variables, particle size, and Sm entrapment efficiency in nanoparticles.

\section{Particle size and polydispersity index (PDI)}

The particle size of the Smnps was determined by photon correlation spectroscopy (PCS) in Zetasizer ${ }^{\circledR}$ Nano ZS against a $4 \mathrm{~mW}$ helium-neon (He-Ne) laser beam, $633 \mathrm{~nm}$, and a back scattering angle of $173^{\circ}$. Particle size and PDI of preparations were determined in triplicate.

\section{Zeta potential}

Zeta potentials were measured using the Zetasizer ${ }^{\circledR}$ Nano ZS using disposable zeta cells. Aliquots from each preparation type were injected in electrophoretic zeta cells and zeta potentials were analyzed using the Smoluchowski equation.

\section{Atomic force microscopy (AFM)}

The morphological examination of the nanoparticles was carried out using a AFM setup. Smnp suspensions $(100 \mu \mathrm{L})$ from different preparations were deposited onto fused mica substrates and the particles were visualized in tapping mode using RTESP tips (Veeco, Santa Barbara, CA) at 267-328 $\mathrm{kHz}$ resonance frequency at a scan speed of $1.2 \mathrm{~Hz}$.

\section{Fourier transform infrared (FTIR) spectroscopy}

FTIR studies were carried out to observe for Sm and polymer interactions if any. Samples of Sm, Eudragit RS100 ${ }^{\circledR}$, and an eutectic mixture were diluted separately with IR grade $\mathrm{KBr}$ in the ratio of 1:100 and were pelletized in a hydraulic press. The pellets were scanned over a wavenumber range of $4000-400 \mathrm{~cm}^{-1}$ and the data stacked in KnowItAll ${ }^{\circledR}$ (Bio-Rad, Hercules, CA) software to compare and search for chemical interactions.

\section{Nanoparticle entrapment efficiency}

$\mathrm{Sm}$ mass encapsulation in nanoparticle was determined from the amount of Sm originally taken and the amount remaining in the supernatant after harvesting. A validated spectrophotometric analysis method was used throughout. Briefly, $100 \mu \mathrm{L}$ of supernatant from each preparation was diluted in $\mathrm{pH} 7.4$ phosphate buffer: methanol, 48:62, v/v and $\mathrm{Sm} \lambda_{\text {max }}$ of $326 \mathrm{~nm}$ was used for analysis. ${ }^{36}$ The limit of determination (LOD) for Sm was observed as $1.167 \mu \mathrm{g} / \mathrm{mL}$ and the limit of quantitation (LOQ) was $3.896 \mu \mathrm{g} / \mathrm{mL}$. Sm entrapment efficiency for each preparation was determined using the formula:

$$
\begin{aligned}
& \text { Sm entrapment }(\%) \\
& =\left(\frac{\text { Mass of Sm originally taken }- \text { Mass of Sm in supernatant }}{\text { Mass of Sm originally taken }}\right) \times 100
\end{aligned}
$$

\section{In vitro release studies}

Smnp equivalent to $5 \mathrm{mg}$ of payload was suspended in $5 \mathrm{~mL}$ of $100 \mathrm{mM}, \mathrm{pH} 7.4$ phosphate buffer and transferred quantitatively in dialysis bags. Lightly tied bags were placed in glass vials containing $100 \mathrm{~mL}$ of phosphate buffer maintained at $37^{\circ} \mathrm{C}$ over a shaking water bath set at $50 \mathrm{rpm}$. At every predetermined time interval, $5 \mathrm{~mL}$ of the buffer medium was withdrawn from the external media and $20 \mathrm{~mL}$ of fresh buffer was added to maintain sink conditions. The amount of Sm released at each time point was estimated spectrophotometrically as described earlier with necessary corrections for the dilution factors. The in vitro release studies for all preparations were completed in triplicate and the cumulative percentage release over time was plotted. In order to understand the release mechanism, the Korsmeyer-Peppas model was applied and release exponent $(n)$ and the constant 
incorporating structural and geometric characteristics of the system (K) values were calculated using SigmaPlot.

\section{Smnp in APAP-induced hepatotoxicity Animal care}

Swiss albino mice (25-30 g) procured from Central Research Institute (Kolkata, India) were used in all experiments. Animals were housed in polypropylene cages in standard laboratory conditions of relative humidity $50 \% \pm 10 \%$, temperature $22^{\circ} \mathrm{C} \pm 2{ }^{\circ} \mathrm{C}$, and $12 / 12$ hour light-dark cycle for 10 days prior to experiments. Access of water was ad libitum and standard pellet food (Hindustan Unilever, Mumbai, India) supply was provided twice a day. All animal experiments were conducted as per the approval and guidelines of the institutional animal ethical committee under the Government of India registration number 506/01/a/ CPCSEA. Mice were fasted for 12 hours before the start of experiments in order to deplete hepatic GSH store. APAP and test drugs were administered intraperitoneally (i.p.) either dissolved or dispersed in saline at $37^{\circ} \mathrm{C}$. Food was restored 1 hour after administration; water, however, was allowed ad libitum.

\section{APAP hepatotoxicity}

Animals were individually weighed and randomly divided into 12 animals per group. Group A, received normal saline and served as the control. APAP hepatotoxicity was induced in Group B animals by single i.p. injection of $300 \mathrm{mg} / \mathrm{kg}^{37}$ and served as positive control. Group $\mathrm{C}$ mice were treated with empty nanoparticles on alternate days for 7 days, prior to administration of APAP. Effects of Sm and Smnp over APAP-induced hepatotoxicity were analyzed. An alternate day treatment protocol was followed in Group D animals receiving $125 \mathrm{mg} / \mathrm{kg}$ of $\mathrm{Sm}$ for 7 days $^{38}$ prior to a single injection of $300 \mathrm{mg} / \mathrm{kg}$ APAP. Similarly, Group E animals were treated with Smnp with an equivalent of $125 \mathrm{mg} / \mathrm{kg} \mathrm{Sm}$ payload for 7 days prior to an injection of APAP. Group F animals received a single injection of $125 \mathrm{mg} / \mathrm{kg} \mathrm{Sm} 1$ hour after APAP-induced hepatotoxicity while group G animals received a single injection of Smnp equivalent to $125 \mathrm{mg} / \mathrm{kg}$ of Sm payload 1 hour after APAP administration.

After 12 hours of APAP injection, animals were anesthetized with anesthetic ether and blood was collected and allowed to coagulate at room temperature. Serum was separated and stored at $-80^{\circ} \mathrm{C}$ for biochemical evaluations. Mice were then euthanized with ether overdose and the liver removed. Portions of the liver from both lobes were quickly dissected, blotted, weighed and stored in $-80^{\circ} \mathrm{C}$. A portion of the liver was preserved in formalin for histological sections. Tissue homogenates $(10 \% \mathrm{w} / \mathrm{v})$ were prepared in ice cold phosphate buffer (50 mM, pH 7.0) containing $0.1 \mathrm{mM}$ ethylenediaminetetraacetic acid (EDTA). Homogenates were further centrifuged at $5000 \mathrm{rpm}$ for 15 minutes at $4^{\circ} \mathrm{C}$ and the supernatant was stored at $-80^{\circ} \mathrm{C}$ until further use.

\section{Biochemical parameters and histopathology}

Biochemical evaluations for hepatic injury were recorded by assessment of different enzyme markers in serum using specific reagent kits. Analytical procedures were followed as directed in the kits. Reduced GSH level was measured from liver homogenate following Ellman's method. ${ }^{39}$ Standard slide preparation techniques were followed for histology and visualization after staining with hematoxylin and eosin.

\section{Statistical analysis}

All experiments were completed in triplicate unless mentioned otherwise and the results were presented as mean \pm standard deviation. Graphs were plotted with the mean values including the error bars. Statistical differences of mean values were analyzed using Student's $t$-test. Differences were considered significant when $P<0.01$.

\section{Results}

Limited solubility and specific polymer association were the major challenges in Sm nanoparticulation. Among many techniques available for drug nanoparticulation; nanoprecipitation takes an interesting advantage of solubility gradient by controlled deposition of both polymer and the drug payload. ${ }^{32}$ The technique also appeared simple and reproducible for later application. The current study has utilized the similar solubility characteristics of polymer Eudragit RS100 ${ }^{\circledR}$ and Sm. ${ }^{31,17,18}$ Eudragit RS100 ${ }^{\circledR}$ has widely been used for ocular nanoparticle drug delivery with good pH stability, biocompatibility, and localization properties. ${ }^{40}$ PVA was used as an efficient stabilizer as it can entrap an array of Eudragit nanoparticles.

There were only a limited number of variables in the nanoprecipitation technique. A $2^{2}$ factorial design study was run to study the effect of Eudragit and PVA mass as independent variables on nanoparticle size and Sm entrapment efficiency. High-low combination batches were tested and particle size, zeta potential, and PDI were recorded (Table 1).

Particles in the vicinity of $100 \mathrm{~nm}$ have a higher possibility for specific tissue localization. ${ }^{41}$ Preparations B2, B3, and B4 
were in the appropriate size range for localization in the liver, whereas preparation B2 carried a higher Sm load. The nanoparticles carried a small positive charge due to a combined effect of the cationic polymer Eudragit RS100 ${ }^{\circledR}$ and the associated stabilizer PVA. A small surface charge was instrumental to keep the nanoparticles stable in solution.

\section{Factorial design}

A $2^{2}$ (two level two factors) factorial design study was used to understand the effects of two independent variables, the amount of Eudragit RS100 ${ }^{\circledR}$ mass $\left(\mathrm{X}_{1}\right)$ and the proportional amount of PVA $\left(\mathrm{X}_{2}\right)$ used over the nanoparticle size range and Sm mass entrapment efficiency. ${ }^{42}$ Results are expressed in equation (1):

$$
\mathrm{Y}_{\mathrm{i}}=\mathrm{b}_{0}+\mathrm{b}_{1} \mathrm{X}_{1}+\mathrm{b}_{2} \mathrm{X}_{2}+\mathrm{b}_{12} \mathrm{X}_{1} \mathrm{X}_{2}
$$

where, $b_{0}$ is the arithmetic mean response for four different preparations and $b_{i}(i=1,2)$ is the estimated coefficient for the factors $X_{i}(i=1,2) . X_{i}(i=1,2)$ denote the effect of changing one factor at a time from its lowest to highest level. The interaction terms $\mathrm{X}_{1} \mathrm{X}_{2}$ signify the effect when both the factors were changed simultaneously. $Y_{i}$ denotes the observation terms of either the particle size or the Sm percentage entrapment efficiency. The values of $F$ were much higher than the critical value for both observation parameters, indicating significance of the model. The final equation regression parameter $\left(R^{2}\right)$ and $P$-values were in agreement with the model parameters and are shown in Table 2 . PVA percentage had a highly significant effect on particle size. The size of nanoparticles made using the nanoprecipitation technique could be controlled by PVA proportion and the mass of polymer incorporated. The interaction effect was negligible and did not pass the significance test (Table 3). Both the PVA concentration and the Eudragit mass had a positive impact on Sm entrapment. The effect of the interaction term was, however, noticeable while considering the Sm entrapment percentage.

\section{AFM studies}

Smnps were evenly distributed in AFM with almost no aggregation. Particles from all preparation types appeared spherical and smooth in surface. AFM study samples from all four preparations are depicted in Figure 1.

\section{FTIR studies}

Sm flavonolignans were evidenced using FTIR analysis by the typical presence of benzopyran ring vibrations at $1084 \mathrm{~cm}^{-1}$ with concomitant presence for out of plane $-\mathrm{C}-\mathrm{H}$ deformations at $821 \mathrm{~cm}^{-1}$ (Figure 2). The reactive flavonolignan ketone ${ }^{43}$ responded at $1636 \mathrm{~cm}^{-1}$ and the aromatic ring stretching vibrations were observed at $1509 \mathrm{~cm}^{-1}$. Eudragit $\mathrm{RS} 100^{\circledR}$ polymer linear branch ketone responded at $1733 \mathrm{~cm}^{-1}$ which associated with linear $-\mathrm{C}-\mathrm{H}$ stretching vibrations at $2849 \mathrm{~cm}^{-1}$. When an eutectic mixture of Sm and Eudragit polymer was analyzed using FTIR, the Sm ketone was unaffected at $1636 \mathrm{~cm}^{-1}$ alongside the polymer ketone stretching at $1733 \mathrm{~cm}^{-1}$, indicating no chemical interaction between Sm and the polymer. In addition, the structurally sensitive Sm benzopyran at $1084 \mathrm{~cm}^{-1}$ and specific Eudragit response at $2849 \mathrm{~cm}^{-1}$ were observable in the Sm-Eudragit blend, which suggests no chemical interactions.

\section{In vitro release}

In vitro release was gradual over time. In the case of Smnp B1 and B2, an initial faster Sm release phase was observed over a period of 8 hours. This was possibly due to nanoparticle surface-adsorbed Sm molecules. Release thereafter was steady and $90 \%$ of the load entrapped was traced during the study period of 200 hours. Preparation $\mathrm{B} 1$ and $\mathrm{B} 2$ release were persistent whereas B4 release was not very stable (Figure 3 ). Polymer mass here appeared an important parameter for Sm entrapment and release profiling and no polymer burst effect was observed during the in vitro release studies. Korsmeyer-Peppas kinetic model was applied for Smnp release up to $60 \%$ of the mass load release. The exponent component $n$ for B2 and B 3 formulation was near 0.4 (Table 4), thus indicating a diffusion-controlled release pattern. ${ }^{44} \mathrm{Sm}$ mass loading in preparation B2 was significantly higher and the B2 in vitro release profile was sufficiently consistent. Smnps of B2 type were therefore chosen for a detailed hepatoprotection evaluation against APAP-induced hepatotoxicity.

Table 2 Summary of regression analysis and ANOVA for measured responses

\begin{tabular}{llllllll}
\hline Observation parameter $\mathbf{Y}$ & $\mathbf{b}_{\mathbf{0}}$ & $\mathbf{b}_{\mathbf{1}}$ & $\mathbf{b}_{\mathbf{2}}$ & $\mathbf{b}_{\mathbf{1 2}}$ & $\mathbf{R}^{\mathbf{2}}$ & $\mathbf{F}$ & $\boldsymbol{P}^{\boldsymbol{\epsilon}}$ \\
\hline Silymarin entrapment \% & 53.13 & 2.06 & 8.12 & -8.20 & 0.9464 & 53.93 & $<0.000 \mathrm{I}$ \\
Particle size nm & 110.70 & -15.72 & -5.58 & +0.47 & 0.9578 & 69.08 & $<0.000 \mathrm{I}$ \\
\hline
\end{tabular}

Note: ${ }^{\epsilon}<0.0001$ indicates highly significant. Abbreviation: ANOVA, analysis of variance. 
Table 3 Effects of process variables on silymarin entrapment and particle size

\begin{tabular}{|c|c|c|c|c|}
\hline $\begin{array}{l}\text { Parameter } \\
\text { terms }\end{array}$ & $\begin{array}{l}\text { Process } \\
\text { variables }\end{array}$ & $\begin{array}{l}\text { Effect on } \\
\text { particle size }\end{array}$ & $\begin{array}{l}\text { Effect on Sm } \\
\text { entrapment }\end{array}$ & $P \pi$ \\
\hline$b_{1}$ & \%PVA & -15.72 & & $<0.000$ I \\
\hline$b_{2}$ & $\begin{array}{l}\text { Eudragit } \\
\text { amount }\end{array}$ & -5.58 & & $<0.0030$ \\
\hline$b_{12}$ & Interaction & +0.47 & & $<0.6992$ \\
\hline$b_{1}$ & \%PVA & & +2.06 & $<0.0668$ \\
\hline$b_{2}$ & $\begin{array}{l}\text { Eudragit } \\
\text { amount }\end{array}$ & & +8.12 & $<0.000$ I \\
\hline$b_{12}$ & Interaction & & -8.20 & $<0.000$ I \\
\hline
\end{tabular}

Notes: $\pi P<0.01$ indicates significant; $P<0.000$ I indicates highly significant. Abbreviations: PVA, polyvinyl alcohol; Sm, silymarin.

\section{APAP hepatotoxicity and liver biochemistry}

Effects of Sm and Smnp on APAP mouse hepatotoxicity are presented in Table 5. A dose of $300 \mathrm{mg} / \mathrm{kg}$ (Group B) established significant hepatotoxicity as evidenced from the elevated levels of marker enzymes compared with the control
Group A. Mortality was recorded in the APAP-treated group. Sm pretreatment (Group D) provided quantitative protection against hepatotoxicity as shown by reduced levels of marker enzymes. Empty nanoparticles without Sm load, however, did not mark any significant change in serum parameters. Pretreatment with Smnp (Group E) endowed a significant reversal of marker enzymes when compared with the APAPtreated group. Additionally, no animal death was recorded in group E.

The levels of reduced GSH in the APAP-treated group were markedly low at $6.9 \pm 1.21 \mu \mathrm{mol} / \mathrm{g}$ of tissue. This was indicative of NAPQI-mediated damage. In the case of Group $\mathrm{D}$ and $\mathrm{E}$, the reduced GSH level was restored to a higher level possibly due to a $\mathrm{Sm}$-mediated regeneration response.

A differential response was recorded when the group $\mathrm{F}$ and group $\mathrm{G}$ animals were administered with Sm or Smnp 1 hour after APAP overdose. Sm failed to elicit significant hepatoprotection. The APAP-elevated levels of marker enzymes and the hepatic GSH levels were not significantly
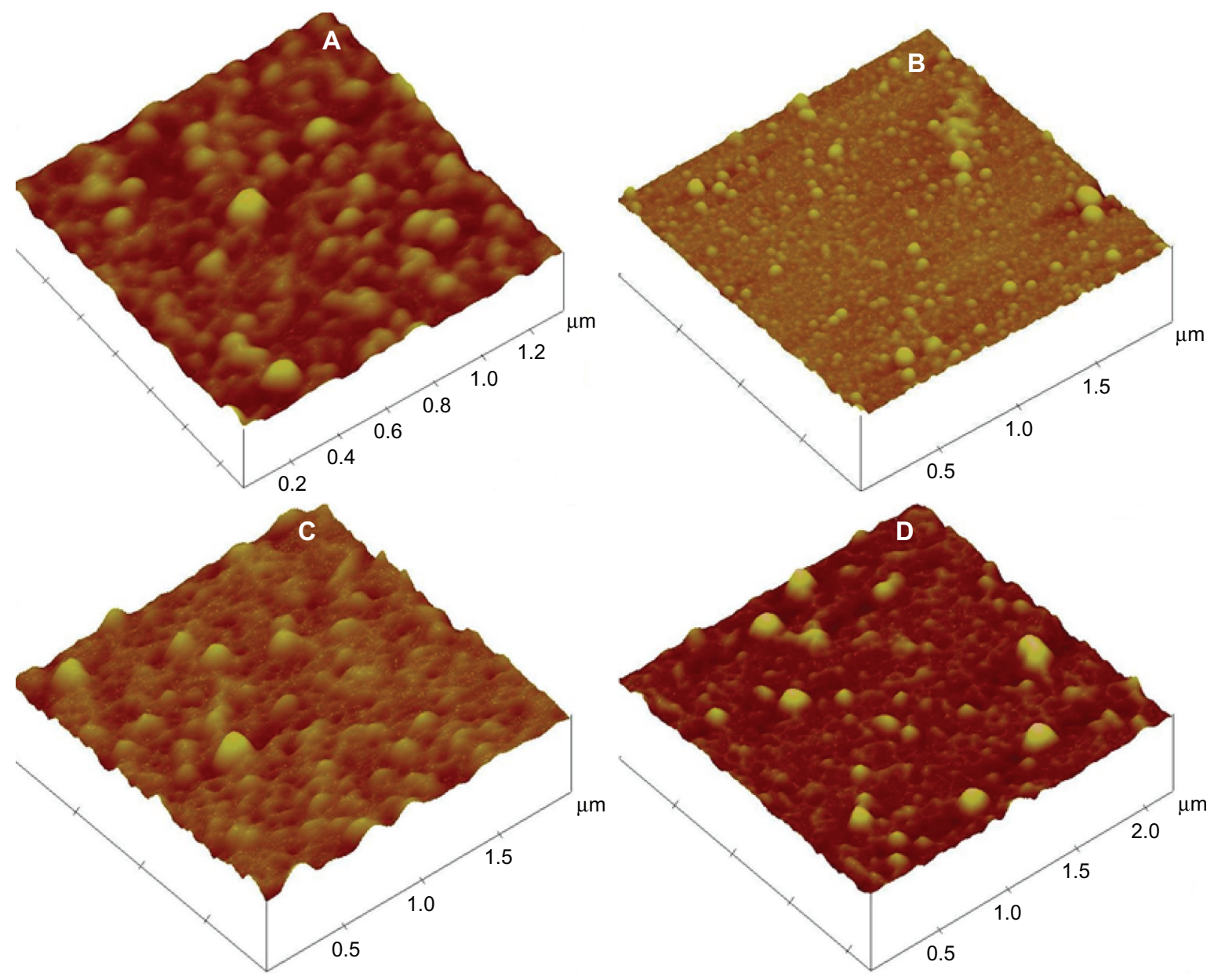

Figure I AFM study of silymarin nanoparticle preparations. Preparation BI (A), Preparation B2 (B), Preparation B3 (C), Preparation B4 (D). Abbreviation: AFM, atomic force microscopy. 


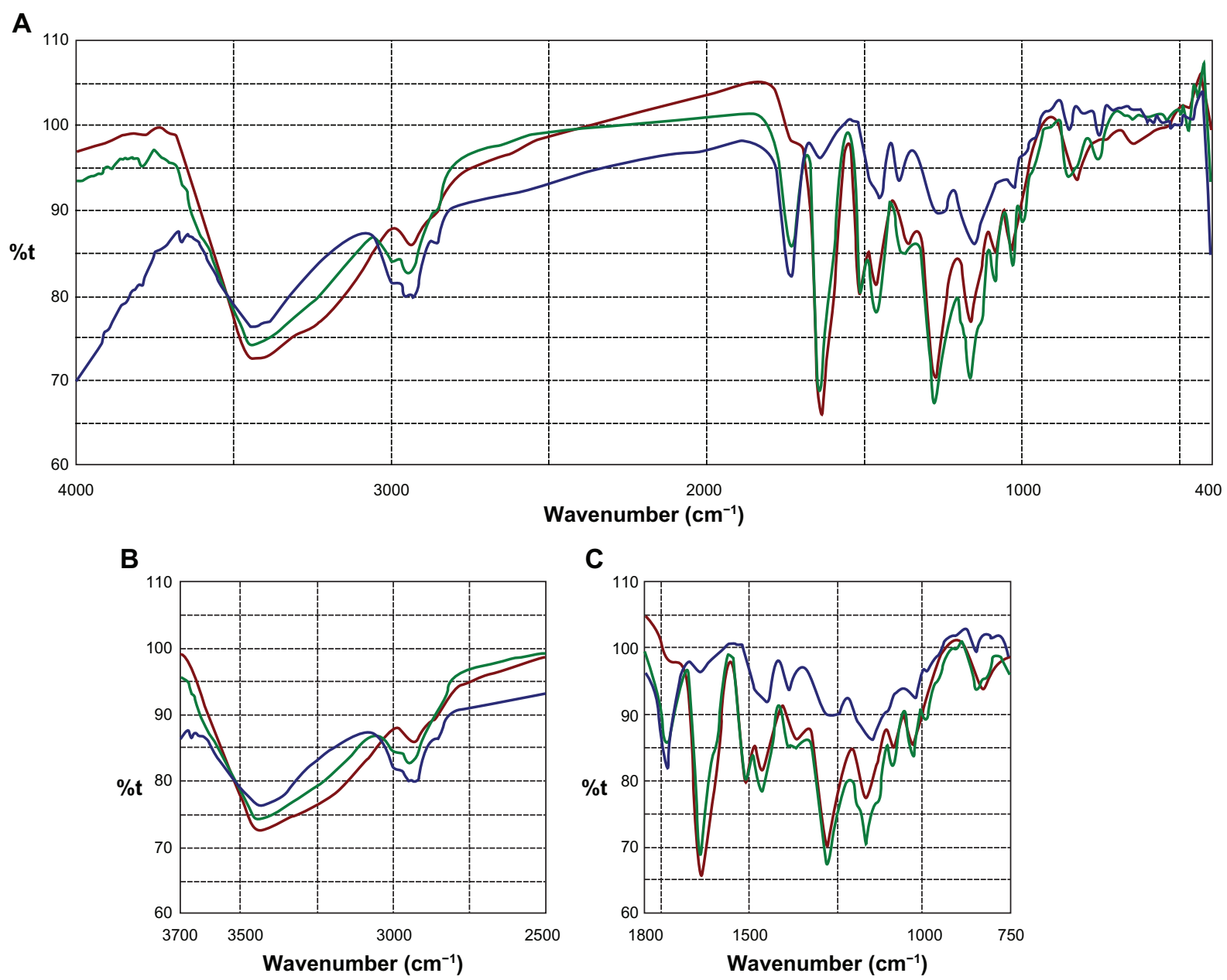

Figure 2 FTIR overlay for silymarin and Eudragit RSI00 ${ }^{\circledR}$. FTIR scan over the entire region (A), comparison zone upfield (B), comparison zone downfield (C). Notes: Color codes - silymarin (brown); Eudragit RSI00 ${ }^{\circledR}$ (green); silymarin-Eudragit RSI00 ${ }^{\circledR}$ (blue).

Abbreviation: FTIR, Fourier transform infrared.

altered. In the case of Smnp, however, hepatic GSH store was restored with concomitant decrease in serum marker enzymes. Perhaps Smnps hepatoprotection was possible due to the rapid localization of nanoparticles in hepatic tissues during the 12-hour exposure period.

\section{Histopathology}

Elevated levels of marker enzymes in serum were an indication of disrupted structural integrity of the hepatocellular membrane which caused leakage of the liver enzymes into the

Table 4 Korsmeyer-Peppas release kinetics for nanoparticles

\begin{tabular}{lll}
\hline Preparation code & \multicolumn{2}{l}{$\begin{array}{l}\text { Korsmeyer-Peppas model } \\
\text { parameters }\end{array}$} \\
\cline { 2 - 3 } & $\mathbf{n}$ value & K value \\
\hline BI & 0.35 & 0.1172 \\
B2 & 0.39 & 0.1099 \\
B3 & 0.41 & 0.0825 \\
B4 & 0.52 & 0.0420 \\
\hline
\end{tabular}

blood due to APAP toxicity. APAP-treated group (Group B) animals demonstrated loss of normal hepatic structure, with necrotic damage which was characterized by the disruption of the lattice nature of the hepatocyte, damaged cell membranes, reduced diameter of nuclei, disintegrated central vein, dilated sinusoids and moderate infiltration of monocytes, and

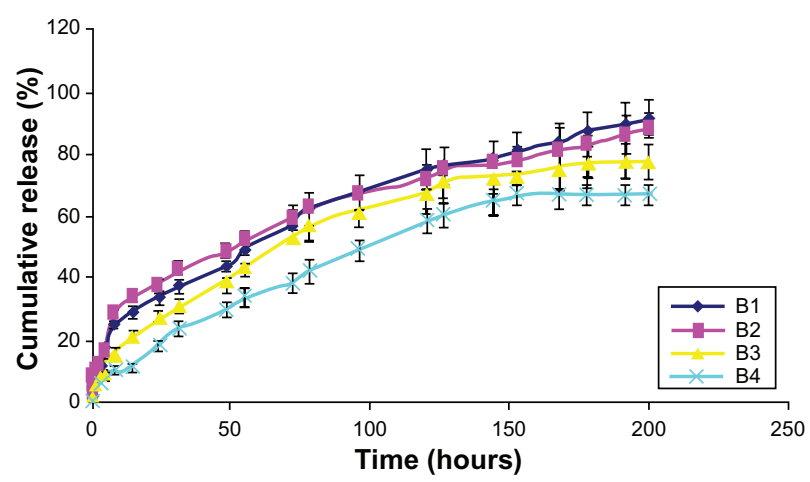

Figure 3 In vitro release studies of silymarin nanoparticles. 
Table 5 Effects of silymarin and silymarin nanoparticles against APAP-induced hepatotoxicity

\begin{tabular}{|c|c|c|c|c|c|}
\hline $\begin{array}{l}\text { Animal } \\
\text { groups }\end{array}$ & AST" (IU/L) & $A L T \pi(I U / L)$ & ALP" $(I U / L)$ & $\begin{array}{l}\text { GSH" }(\mu \mathrm{mol} / \mathrm{g} \\
\text { of tissue })\end{array}$ & $\begin{array}{l}\text { Mortality } \\
\text { (dead/total) }\end{array}$ \\
\hline A & $51.7 \pm 3.2^{\mathrm{x}}$ & $86.2 \pm 8.6^{\aleph}$ & $116.2 \pm 8.6^{k}$ & $16.8 \pm 0.3^{x}$ & $0 / 12$ \\
\hline B & $4943.3 \pm 220.5$ & $5161.7 \pm 339.8$ & $2161.7 \pm 129.1$ & $6.9 \pm 1.21$ & $6 / 12$ \\
\hline C & $4703.2 \pm 392.3^{¥}$ & $5015.0 \pm 411.6^{*}$ & $2065.0 \pm 178 . I^{*}$ & $6.7 \pm 1.5^{\zeta}$ & $6 / 12$ \\
\hline D & $700.7 \pm 46.9^{x}$ & $785.2 \pm 85.5^{\mathrm{K}}$ & $385.2 \pm 35.7^{\aleph}$ & $13.8 \pm 1.4^{\mathrm{K}}$ & $0 / 12$ \\
\hline E & $352.4 \pm 77.9^{x}$ & $437.2 \pm 87.8^{\aleph}$ & $237.3 \pm 27.8^{\aleph}$ & $14.6 \pm 1.3^{x}$ & $0 / 12$ \\
\hline $\mathrm{F}$ & $3956.2 \pm 250.8^{\aleph}$ & $4371.4 \pm 229.5^{\aleph}$ & $186 \mid .2 \pm 109.5^{\aleph}$ & $8.3 \pm 0.7^{\aleph}$ & $4 / 12$ \\
\hline G & $553.1 \pm 25.1^{x}$ & $581.8 \pm 33.7^{\aleph}$ & $395.7 \pm 33.2^{\mathrm{K}}$ & $11.3 \pm 0.9^{x}$ & $0 / 12$ \\
\hline
\end{tabular}

Notes: "Results expressed as mean $\pm S D(n=12)$; ${ }^{\circledR} P<0.01$ significant difference compared with Group $B ;{ }^{*} P<0.5$ no significant difference compared with Group $B$; $\zeta P<0.8$ no significant difference compared with Group B.

Abbreviations: ALP, alkaline phosphatase; ALT, alanine transaminase; APAP, paracetamol; AST, aspartate transaminase; GSH, glutathione; SD, standard deviation.

neutrophils in the cytoplasm (Figure 4B). The Sm-treated group (Group D) showed improved histological changes in comparison to Group B animals. This was implied by the presence of mild necrotic lesions (Figure 4D). Smnp-treated groups (Figures $4 \mathrm{E}$ and $4 \mathrm{~F}$ ), however, showed significant regeneration, visible by the presence of increased numbers of hepatocytes and lack of any prominent centrilobular necrosis or sinusoidal congestion. The inflammatory cell infiltration caused by APAP was also significantly decreased following Smnp treatment.

\section{Discussion}

Antihepatotoxic activity of $\mathrm{Sm}$ is due to a synchronous effect of principal flavonolignans. ${ }^{45}$ Our initial attempts in Sm nanoparticulation with poly(lactic-co-glycolic acid) (PLGA) ${ }^{46}$ casein, and alginate ${ }^{47}$ were unsuccessful due to very low Sm mass loading. Eudragit RS100 ${ }^{\circledR}$ is a safe and biocompatible polycation and has previously been used in ophthalmic nanoparticle delivery devices. ${ }^{31,48}$ PVA resulted in a lowering of interfacial tension and nanoparticle steric and mechanical stabilization. ${ }^{32}$ The effect of PVA concentration in particle sizing was shown in factorial design experiments. Higher initial concentration of PVA resulted in smaller particles. Similar PVA-induced stabilization effects have been reported by others in the case of PLGA nanoparticles. ${ }^{49,50} \mathrm{Sm}$ payloading on the other hand was not dependent on any one parameter and the effect of the interaction term was significant. AFM details indicated smooth and spherical particles in all cases of PVA stabilized Eudragit nanoparticles. Chemical interaction studies in FTIR indicated no significant peak shifts for $\mathrm{Sm}$ in the presence of the entrapment polymer Eudragit RS100 ${ }^{\circledR}$. Structurally reactive $\mathrm{Sm}$ ketone and benzopyran groups responded strongly at $1636 \mathrm{~cm}^{-1}$ and $1084 \mathrm{~cm}^{-1}$, both as free compounds and in the Eudragit polymer mixture environment.

Smnps exhibited a sustained release profile and type B1 and B2 accounted for a $90 \%$ payload release during the 200 hours of the in vitro study period. The biphasic Sm release was possibly due to nanoparticle surface-adsorbed molecules, low aqueous solubility of $\mathrm{Sm}$, and the insoluble nature of the polymer. Smnp B2 type carried a higher payload and was selected for detailed APAP-induced mouse hepatotoxicity studies.

APAP hepatotoxicity is primarily due to the pharmacokinetic generation of the reactive metabolite NAPQI. ${ }^{5}$ NAPQI binds to cellular macromolecules causing the collapse of cell membranes and subsequent cell death. A dose of $300 \mathrm{mg} / \mathrm{kg}$ APAP resulted in profound hepatotoxicity and correlated well with the rise in serum aspartate transaminase (AST), $4943.3 \pm 220.5 \mathrm{IU} / \mathrm{L}$, and alanine transaminase (ALT), $5161.7 \pm 339.8 \mathrm{IU} / \mathrm{L}$ levels. Test compounds were i.p. administered and the serum enzyme levels were monitored as markers for hepatic conditions. Hepatic GSH store was monitored (Table 5), as the increased level of NAPQI is linked directly to depletion of hepatic GSH store. ${ }^{6}$ APAP inflicted a rapid depletion of GSH store within 1 hour of treatment. ${ }^{51}$ Higher doses of APAP generate NAPQI, an oxidative product of cytochrome p450, in hepatocytes. GSH can neutralize the highly electrophilic NAPQI but in conditions of depleted GSH stores, NAPQI leads to a cascade of adverse events leading to the generation of reactive oxygen species, membrane protein damage, and adenosine triphosphate (ATP) depletion leading to hepatic necrosis. ${ }^{52}$ Other contributing factors for APAP necrosis are intracellular $\mathrm{Ca}^{2+}$ imbalance and activation of inflammatory mediators such as tumor necrosis factor alpha (TNF- $\alpha)^{6,53}$

Sm possesses strong free radical scavenging activity, inhibits lipid peroxidation, and promotes regeneration of damaged hepatocytes. This effect is due to the increased synthesis rate of ribosomal RNA (rRNA) for the activation of RNA polymerase. In addition, Sm inhibits the 5-lipoxygenase pathway and prevents liver fibrosis. Sm also possesses membrane stabilizing properties ${ }^{54}$ and 

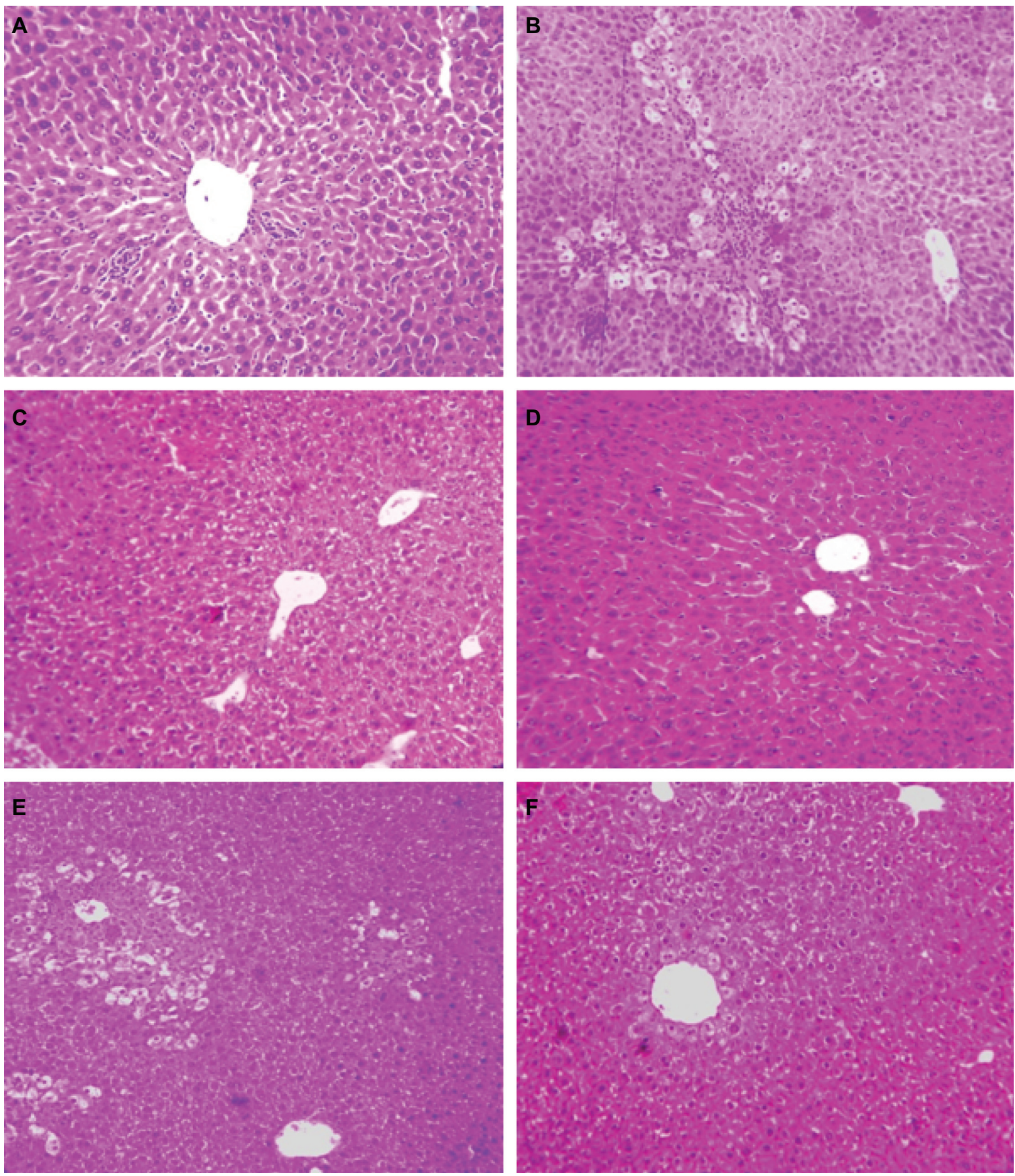

Figure 4 Liver histology $(\mathrm{IOX})$ in mice. Normal control (A), APAP only treated (B), APAP on silymarin pretreatment (C), APAP on silymarin nanoparticle pretreatment (D), silymarin posttreatment and APAP (E), silymarin nanoparticle posttreatment and APAP (F).

Abbreviation: APAP, paracetamol.

these factors together contribute to its hepatoprotective activity.

Group D and group E animals pretreated with Sm or Smnp did not show a marked increase in serum marker enzymes. Hepatic GSH level did not decline and 100\% survival was recorded. Smnp provided an incremental improvement over $\mathrm{Sm}$ in serum marker enzyme levels. This was likely due to Sm-induced membrane stabilization effects. These observations corroborated well with the histological examinations of treated and control groups (Figure 4B, 4E, and 4F). However, when Sm was administered 1 hour after established APAP-induced hepatic necrosis ${ }^{55}$ there was no significant lowering of serum marker enzymes. Necrosis and damage were also observed in the liver. Animal mortality 
recorded was significant and comparable to that of group B. Group G animals, however, when treated with Smnp 1 hour after APAP challenge survived and serum transaminase factors reverted to a lower concentration. A significant amount of hepatic GSH was also recorded.

$\mathrm{Sm}$ is membranotropic in nature, and Sm flavonolignans are known to exert a differential hepatic membrane stabilization response. ${ }^{54}$ Silibin, a major component of $\mathrm{Sm}$, is known to induce dual perturbation on membrane bilayers. ${ }^{56}$ Silibin effects a concentration-dependent transition of bilayers to micellar structure. Isolated membrane studies have provided ample evidence that Sm prevents membrane disruption with increasing concentration. Silibin protective effects were, however, far less marked and were independent of the concentration gradient. Nanoparticle synchronous delivery therefore is important and exerts hepatoprotection activity in case of APAP overdose. Moreover, it can be reasoned that Smnp-induced rapid replenishment of hepatic nonprotein-SH concentration was due to particle effects. Sm flavonolignans are known to increase nuclear rRNA synthesis to a significant level within 8 hours of injection. ${ }^{23}$ Biopharmaceutic enhancement of Sm through nanoparticulation can therefore provide a significant solution for conditions of acute APAP poisoning.

\section{Conclusion}

A new nanoparticle delivery device for Sm in Eudragit RS $100^{\circledR}$ was successfully designed and protective properties against APAP-induced hepatotoxicity were established. Increased Smnp-induced rapid regeneration of hepatic GSH levels was demonstrated, along with downregulation of serum enzyme parameters, and marked increase in survival even when administered after APAP-induced hepatic damage. This appeared possible due to nanoparticle-assisted improved solubilization of Sm.

\section{Acknowledgments}

The authors are thankful to Anirban Chakraborty for his assistance in AFM studies. Financial assistance to Suvadra Das and Partha Roy from the Council of Scientific and Industrial Research (CSIR), India, and Indian Council Of Medical Research (ICMR), respectively, is gratefully acknowledged. Partial support from the Department of Biotechnology, Government of India, is also acknowledged.

\section{Disclosure}

The authors report no conflicts of interest in this work.

\section{References}

1. Knight TR, Fariss MW, Farhood A, Jaeschke H. Role of lipid peroxidation as a mechanism of liver injury after acetaminophen overdose in mice. Toxicol Sci. 2003;76(1):229-236.

2. Zimmerman HJ, Maddrey WC. Acetaminophen (paracetamol) hepatotoxicity with regular intake of alcohol: analysis of instances of therapeutic misadventure. Hepatology. 1995;22(3):767-773.

3. Nolan CM, Sandblom RE, Thummel K, Slattery JT, Nelson SD. Hepatotoxicity associated with acetaminophen usage in patients receiving multiple drug therapy for tuberculosis. Chest. 1994;105(2):408-411.

4. Breen KJ, Bury RW, Desmond PV, Forge BH, Marshford ML, Whelan G. Paracetamol self-poisoning: diagnosis, management, and outcome. Med J Aust. 1982;1(2):77-79.

5. Dahlin DC, Miwa GT, Lu AY, Nelson SD. N-acetyl-p-benzoquinone imine: a cytochrome P-450-mediated oxidation product of acetaminophen. Proc Natl Acad Sci U S A. 1984;81(5):1327-1331.

6. Vermeulen NPE, Bessems JGM, Van de Straat R. Molecular aspect of paracetamol-induced hepatotoxicity and its mechanism based prevention. Drug Metab Rev. 1992;24(3):367-407.

7. Kaushal R, Dave KR, Katyare SS. Paracetamol hepatotoxicity and microsomal function. Environ Toxicol Pharmacol. 1999;7(1):67-74.

8. Wagner H, Diesel P, Seitz M. Chemistry and analysis of silymarin from Silybum marianum Gaertn. Arzneimittelforschung. 1974;24(4): 466-471. German.

9. Hahn G, Lehmann HD, Kurten N, Uebel H, Vogel G. On the pharmacology and toxicology of silymarin, an antihepatotoxic active principle from Silybum marianum (L.) Gaertn. Arzneimittelforschung. 1968;18(6):698-704. [German].

10. Corchete P. Silybum marianum (L.) Gaertn: the source of silymarin. In: Ramawat KG, Merillon JM, editors. Bioactive Molecules and Medicinal Plants. Berlin, Germany: Springer-Verlag; 2008:124-140.

11. Lee JI, Narayan M, Barrett JS. Analysis and comparison of active constituents in commercial standardized silymarin extracts by liquid chromatography-electrospray ionization mass spectrometry. J Chromatogr B Analyt Technol Biomed life Sci. 2007;845(1):95-103.

12. Shibano M, Lin AS, Itokawa $H$, Lee KH. Separation and characterization of active flavonolignans of Silybum marianum by liquid chromatography connected with hybrid ion-trap and time-of-flight mass spectrometry (LC-MS/IT-TOF). J Nat Prod. 2007;70(9):1424-1428.

13. Kvasnicka F, Bíba B, Sevcík R, Voldrich M, Krátká J. Analysis of the active components of silymarin. J Chromatogr A. 2003;990(1 Pt 2): 239-245.

14. Ramasamy K, Agarwal R. Multitargeted therapy of cancer by silymarin. Cancer Lett. 2008;269(2):352-362.

15. Kaur M, Agarwal R. Silymarin and epithelial cancer chemoprevention: how close we are to bedside?. Toxicol Appl Pharmacol. 2007;224(3): 350-359.

16. Gabetta B, Bombardelli E, Pifferi G, inventor; Inverni Della Beffa S.p.A., assignee. Complexes of flavonolignans with phospholipids, preparation thereof and associated pharmaceutical compositions. United States patent US 4764508. 1988 Aug 16.

17. Madaus RH, Halbach G, Trost W, inventor; Dr. Madaus and Co, assignee. Salt of the silymarin group with aminopolyhydroxy alcohols. United States patent US 3994925. 1976 Nov 30.

18. Schulz HU, Schurer M, Krumbiegel G, Wachter W, Weyhenmeyer R, Seidel G. The solubility and bioequivalence of silymarin preparations. Arzneimittelforschung. 1995;45(1):61-64. [German].

19. Woo JS, Kim TS, Park JH, Chi SC. Formulation and biopharmaceutical evaluation of silymarin using SMEDDS. Arch Pharm Res. 2007;30(1): 82-89.

20. Zhang HL, Bai TC, Yan GB, Hu YJ. Solubility of silybin in aqueous poly(vinylpyrrolidone) solution. Fluid Phase Equilibr. 2005;238(2): 186-192.

21. Comoglio A, Tomasi A, Malandrino S, Poli G, Albano E. Scavenging effect of silipide, a new silybin-phospholipid complex, on ethanolderived free radicals. Biochem Pharmacol. 1995;50(8):1313-1316. 
22. EI-Samaligy, Afifi NN, Mahmoud EA. Evaluation of hybrid liposomes-encapsulated silymarin regarding physical stability and in vivo performance. Int J Pharm. 2006;319(1 Pt 2):121-129.

23. Sonnenbichler J, Mattersberger J, Rosen H. Stimulation of RNA synthesis in rat liver and isolated hepatocytes by silybin, an antihepatotoxic agent from Silybum marianum L. Gaertn. Hoppe Seylers Z Physiol Chem. 1976;357(8):1171-1180. [German].

24. Shaker E, Mahmoud H, Mnaa S. Silymarin, the antioxidant component and Silybum marianum extracts prevent liver damage. Food Chem Toxicol. 2010;48(3):803-806.

25. Saliou C, Rihn B, Cillard J, Okamoto T, Packer L. Selective inhibition of NF-kappa-B activation by the flavonoid hepatoprotector silymarin in HepG2: evidence for different activating pathways. FEBS Lett. 1998; 440(1 Pt 2):8-12.

26. Dehmlow C, Erhard J, de Groot H. Inhibition of Kupffer cell functions as an explanation for the hepatoprotective properties of silybinin. Hepatology. 1996;23(4):749-754.

27. Campos R, Garrido A, Guerra R, Valenzuela A. Silybin dihemisuccinate protects against glutathione depletion and lipid peroxidation induced by acetaminophen on rat liver. Planta Med. 1989;55(5):417-419.

28. Muriel P, Garciapina T, Perez-Alvarez V, Mourelle M. Silymarin protects against paracetamol-induced lipid peroxidation and liver damage. J Appl Toxicol. 1992;12(6):439-442.

29. Nencini C, Giorgi G, Micheli L. Protective effect of silymarin on oxidative stress in rat brain. Phytomedicine. 2007;14(2 Pt 3):129-135.

30. Ubrich N, Schmidt C, Bodmeier R, Hoffman M, Maincent P. Oral evaluation in rabbits of cyclosporin-loaded Eudragit RS or RL nanoparticles. Int J Pharm. 2005;288(1):169-175.

31. Pignatello R, Bucolo C, Ferrara P, Maltese A, Puleo A, Puglisi G. Eudragit RS100 nanosuspensions for the ophthalmic controlled delivery of ibuprofen. Eur J Pharm Sci. 2002;16(1 Pt 2):53-61.

32. Galindo-Rodriguez S, Allémann E, Fessi H, Doelker E. Physicochemical parameters associated with nanoparticle formation in the salting-out, emulsification-diffusion, and nanoprecipitation methods. Pharm Res 2004;21(8):1428-1439.

33. Miller RP, Fischer LJ. Urinary excretion of acetaminophen by the rat. J Pharm Sci. 1974;63(6):969-970.

34. Prescott LF. Factors influencing paracetamol metabolism. In: Prescott LF, editor. Paracetamol (Acetaminophen): a Critical Bibliographic Review. London, UK: Taylor and Francis; 1996:708-715.

35. Govender T, Stolnik S, Garnett MC, Illum L, Davis SS. PLGA nanoparticles prepared by nanoprecipitation: drug loading and release studies of a water soluble drug. J Control Release. 1999;57(2): $171-185$.

36. Maheshwari H, Agarwal R, Patil C, Katare OP. Preparation and pharmacological evaluation of silibinin liposomes. Arzneimittelforschung. 2003;53(6):420-427.

37. Hinson JA, Pike SL, Pumford NR, Mayeux PR. Nitrotyrosine-protein adducts in hepatic centrilobular areas following toxic doses of acetaminophen in mice. Chem Res Toxicol. 1998;11(6):604-607.

38. Singha PK, Roy S, Dey S. Protective activity of andrographolide and arabinogalactan proteins from Andrographis paniculata Nees. against ethanol-induced toxicity in mice. J Ethnopharmacol. 2007;111(1): 13-21.

39. Ellman GL. Tissue sulfhydryl groups. Arch Biochem Biophys. 1959; 82(1):70-77.
40. Pignatello R, Bucolo C, Puglisi G. Ocular tolerability of Eudragit RS100 and RL100 nanosuspensions as carriers for ophthalmic controlled drug delivery. J Pharm Sci. 2002;91(12):2636-2641.

41. Lanjuan L, Huaying W, Zhan YO, et al. Polymer- and lipid-based nanoparticle therapeutics for the treatment of liver diseases. Nano Today. 2010;5(4):296-312.

42. Armstrong NA, James KC. Pharmaceutical Experimental Design And Interpretation. London, UK: Taylor and Francis; 1996:131-134.

43. Bellamy LJ. The Infrared Spectra of Complex Molecules. 3rd ed, Vol 1. London, UK: Chapman and Hall; 1975:107-128.

44. Lin CC, Metters AT. Hydrogels in controlled release formulations: network design and mathematical modeling. Adv Drug Deliv Rev. 2006;58(12 Pt 13):1379-1408.

45. Lu C, Lu Y, Chen J, Zhang W, Wu W. Synchronized and sustained release of multiple components in silymarin from erodible glyceryl monostearate matrix system. Eur J Pharm Biopharm. 2007;66(2): 210-219.

46. Roy P, Das S, Bera T, Mondol S, Mukherjee A. Andrographolide nanoparticles in leishmaniasis: characterization and in vitro evaluations. Int J Nanomedicine. 2010;5:1113-1121.

47. Bhowmik BB, Sa B, Mukherjee A. Preparation and in vitro characterization of slow release testosterone nanocapsules in alginates. Acta Pharm. 2006;56:417-429.

48. Pignatello R, Bucolo C, Spedalieri G, Maltese A, Puglisi G. Flurbiprofenloaded acrylate polymer nanosuspensions for ophthalmic application. Biomaterials. 2002;23(15):3247-3255.

49. Vandervoort J, Ludwig A. Biocompatible stabilizers in the preparation of PLGA nanoparticles: a factorial design study. Int J Pharm. 2002; 238(1 Pt 2):77-92.

50. Murakami H, Kawashima Y, Niwa T, Hino T, Takeuchi H, Kobayashi M. Influence of the degrees of hydrolyzation and polymerization of poly(vinylalcohol) on the preparation and properties of poly(DL -lactide-co-glycolide) nanoparticle. Int J Pharm. 1997;149: 43-49.

51. Miner DJ, Kissinger PT. Evidence for the involvement of N-acetyl-pquinoneimine in acetaminophen metabolism. Biochem Pharmacol. 1979;28(22):3285-3290.

52. Mitchell JR, Jollow DJ, Potter WZ, Gillette JR, Brodie BB. Acetaminophen-induced hepatic necrosis. IV. Protective role of glutathione. J Pharmacol Exp Ther. 1973;187(1):211-217.

53. Martin-Murphy BV, Holt MP, Ju C. The role of damage associated molecular pattern molecules in acetaminophen-induced liver injury in mice. Toxicol Lett. 2010;192(3):387-394.

54. Basiglio CL, Sánchez Pozzi EJ, Mottino AD, Roma MG. Differential effects of silymarin and its active component silibinin on plasma membrane stability and hepatocellular lysis. Chem Biol Interact. 2009;179(2 Pt 3):297-303.

55. Roberts DW, Bucci TJ, Benson RW, et al. Immunohistochemical localization and quantification of the 3-(cystein-S-yl)-acetaminophen protein adduct in acetaminophen hepatotoxicity. Am J Pathol. 1991; 138(2):359-371.

56. Wesolowska O, Lania-Pietrzak B, Kuzdzal M, et al. Influence of silybin on biophysical properties of phospholipid bilayers. Acta Pharmacol Sin. 2007;28(2):296-306.
International Journal of Nanomedicine

\section{Publish your work in this journal}

The International Journal of Nanomedicine is an international, peerreviewed journal focusing on the application of nanotechnology in diagnostics, therapeutics, and drug delivery systems throughou the biomedical field. This journal is indexed on PubMed Central,

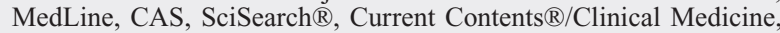

\section{Dovepress}

Journal Citation Reports/Science Edition, EMBase, Scopus and the Elsevier Bibliographic databases. The manuscript management system is completely online and includes a very quick and fair peer-review system, which is all easy to use. Visit http://www.dovepress.com/ testimonials.php to read real quotes from published authors. 